\title{
Anatomic distribution of deep vein thrombosis in pregnancy
}

\author{
Wee-Shian Chan MD MSc, Frederick A. Spencer MD, Jeffrey S. Ginsberg MD
}

Previously published at www.cmaj.ca

$\infty \infty$

See related commentary by Kaaja, page 649

\section{ABSTRACT}

Background: Prospective studies of nonpregnant patients have demonstrated that most deep vein thromboses of the lower extremity originate in the calf veins and progress proximally, but the anatomic distribution of thromboses in pregnant patients is unclear. An understanding of the anatomic distribution of deep vein thrombosis in pregnancy has important implications for optimizing diagnostic imaging protocols. We undertook this study to determine the anatomic distribution of deep vein thrombosis of the lower extremity in symptomatic pregnant patients.

Methods: We systematically searched MEDLINE (1966 to January 2009), Embase (1980 to January 2009) and the Cochrane Library using prespecified criteria to identify articles providing objective diagnostic and anatomic information for unselected or consecutive symptomatic pregnant patients with deep vein thrombosis.

Results: Six articles from an initial list of 1098 titles met the inclusion criteria. These articles provided information for 124 pregnant women with a diagnosis of deep vein thrombosis. Overall, involvement of the left leg was reported in $84(88 \%)$ of the 96 patients for which the side affected was known, and $87(71 \%)$ of 122 thromboses were restricted to the proximal veins without involvement of the calf veins. Among these cases of proximal deep vein thrombosis, $64 \%$ $(56 / 87)$ were restricted to the iliac and/or femoral vein.

Conclusion: Despite a paucity of studies in this area, the results of our review suggest that the anatomic distribution of deep vein thrombosis in pregnant women differs from that for nonpregnant patients. In addition to what was previously known - that left-sided deep vein thrombosis is more common in pregnancy - we also found that proximal deep vein thrombosis restricted to the femoral or iliac veins is also more common (> $60 \%$ of cases). If confirmed by larger studies, these findings could affect our understanding of the pathophysiology and derivation of diagnostic algorithms for examination of pregnant women with suspected deep vein thrombosis.

$\mathrm{T}$ he knowledge that deep vein thrombosis most commonly develops in the calf and then extends proximally $^{1-5}$ was critical in the development of diagnostic strategies for this condition using compression ultrasonography. Relative to venography (the reference standard), compression ultrasonography is highly sensitive (97\%) for throm- bosis of the proximal veins, ${ }^{6}$ but it is less sensitive for thrombosis limited to the calf. To minimize the risk of missing isolated deep vein thromboses in the calf that subsequently propagate proximally, limited serial compression ultrasonography (over 7 days) has been advocated. ${ }^{7.8}$ Knowing that thrombosis progresses proximally and that the thrombus is usually contiguous has allowed clinicians to limit compression ultrasonography examinations for patients with suspected deep vein thrombosis to two points along the venous system: the common femoral vein and the popliteal vein., ${ }^{910}$

The applicability and performance of diagnostic techniques involving compression ultrasonography for pregnant patients with deep vein thrombosis is less clear. Because of the risks associated with exposing the fetus to radiation and concerns related to administering contrast agent, few studies in pregnancy have used venography. In addition, there have been no prospective studies validating the use of compression ultrasonography for the diagnosis of deep vein thrombosis in pregnant patients. ${ }^{11}$ Currently, diagnostic imaging algorithms for deep vein thrombosis in pregnant patients are often extrapolated from studies of the nonpregnant population. ${ }^{12}$ This presumes that the pathophysiology, distribution and progression of deep vein thrombosis in pregnant patients are similar to those seen in nonpregnant patients.

Observational studies ${ }^{13}$ have suggested that the anatomic distribution of deep vein thrombosis may in fact differ among pregnant patients. During pregnancy, deep vein thrombosis of the left leg is predominant, ${ }^{13}$ and isolated thrombosis of the iliac vein is reported to occur. ${ }^{14}$ The ideal study design to investigate the distribution of deep vein thrombosis among pregnant women might involve systematic leg venography for pregnant patients with acute deep vein thrombosis, but such a study is not feasible for ethical reasons, since it would involve exposing fetuses to contrast agent and ionizing radiation. Consequently, we undertook a systematic review of previously published studies of cohorts of pregnant women with deep vein thrombosis to build on our prior findings ${ }^{12,13}$ and to better describe the anatomic distribution of deep vein thrombosis in pregnancy.

From the Department of Medicine (Chan), University of Toronto, Toronto, Ont.; and the Department of Medicine (Spencer, Ginsberg), McMaster University, Hamilton, Ont.

CMAJ 2010. DOI:10.1503/cmaj.091692 


\section{Method}

\section{Literature review}

Two of us (W.S.C., F.A.S.) performed a systematic search of MEDLINE (1966 to January 2009), Embase (1980 to January 2009) and the Cochrane Library with the search terms "deep vein thrombosis" and "venous thromboembolism"; the search was limited to English articles. We scanned the title and abstract of each article initially retrieved for content. We then studied articles that provided diagnostic information for unselected or consecutive women presenting with acute deep vein thrombosis of the lower extremity during pregnancy for suitability for data abstraction. Articles eligible for data abstraction were case series or observational cohorts of three or more participants (the minimum number of three being used to avoid reporting bias) in which deep vein thrombosis was diagnosed in unselected or consecutive pregnant women by means of objective techniques such as compression ultrasonography, magnetic resonance imaging, computed tomography or venography.

\section{Data abstraction and analysis}

Two of us (W.S.C., F.A.S.) abstracted data from eligible articles, including the side of the thrombosis (left, right or both) and the anatomic distribution of the thrombosis as revealed by diagnostic testing. We also specifically abstracted information on the involvement of each venous segment (iliac, femoral, popliteal and calf veins) at the time deep vein thrombosis was diagnosed. Any discrepancies were resolved by discussion. We used descriptive statistics to present our findings.

\section{Results}

We retrieved 933 articles from MEDLINE and 165 articles from Embase, but no articles from the Cochrane Library. After reviewing the abstracts, we retrieved 21 potentially eligible articles relating to unselected series of consecutive women with a diagnosis of deep vein thrombosis during pregnancy. Of these articles, three were excluded because impedance plethysmography was used to diagnose deep vein thrombosis, ${ }^{15-17}$ nine were excluded because the anatomic description of the thrombi was inadequate, ${ }^{18-26}$ one was excluded because of patient selection bias, ${ }^{27}$ and two were excluded because of potential duplication of reporting. ${ }^{28,29} \mathrm{We}$ abstracted data from the remaining six articles ${ }^{30-35}$ (Table 1).

Five of these articles ${ }^{30-34}$ were retrospective case series, each from a single site, one of which reported results for both a retrospective cohort and a prospective cohort of patients. ${ }^{33}$ The remaining article was a report from a registry of 183 medical centres. ${ }^{35}$ The number of patients in each of the case series or cohorts was small (range 4 to 34 patients). The earlier studies, published more than 18 years ago, ${ }^{30-33}$ reported primarily on the use of venography to diagnose deep vein thrombosis in pregnant

Table 1: Characteristics of studies reporting the anatomic distribution of deep vein thrombosis (DVT) in pregnant patients

\begin{tabular}{|c|c|c|c|c|}
\hline Reference & Study design & Patient recruitment & Patient characteristics & $\begin{array}{l}\text { Diagnostic } \\
\text { modality }\end{array}$ \\
\hline Bergqvist et al. ${ }^{30}$ & $\begin{array}{l}\text { Retrospective } \\
\text { cohort }\end{array}$ & $\begin{array}{l}\text { Consecutive patients diagnosed at } \\
\text { one centre, 1974-1980 }\end{array}$ & $\begin{array}{l}\text { Mean age } 26 \text { (range 17-41) yr } \\
\text { First trimester: } 4 \\
\text { Second trimester : } 7 \\
\text { Third trimester: } 6\end{array}$ & Venography \\
\hline Bergqvist et al. ${ }^{31}$ & $\begin{array}{l}\text { Retrospective } \\
\text { cohort }\end{array}$ & $\begin{array}{l}\text { Consecutive patients referred to a } \\
\text { thrombosis clinic at one centre, with } \\
\text { diagnosis of DVT, 1970-1979 }\end{array}$ & $\begin{array}{l}\text { Mean age } 26 \text { (range 19-42) yr } \\
\text { First trimester: } 6 \\
\text { Second trimester: } 11 \\
\text { Third trimester: } 10 \\
\text { Unknown: } 3\end{array}$ & Venography \\
\hline Greer et al. ${ }^{32}$ & $\begin{array}{l}\text { Retrospective } \\
\text { cohort }\end{array}$ & $\begin{array}{l}\text { Consecutive patients with suspected } \\
\text { DVT, referred for compression } \\
\text { ultrasonography of the leg over a } \\
\text { two-year period }\end{array}$ & $\begin{array}{l}\text { Mean age } 31 \text { (range 29-33) yr } \\
\text { First trimester: } 0 \\
\text { Second trimester: } 1 \\
\text { Third trimester: } 3\end{array}$ & $\begin{array}{l}\text { Compression } \\
\text { ultrasonography, } \\
\text { venography }\end{array}$ \\
\hline Aburahma et al..$^{34}$ & $\begin{array}{l}\text { Retrospective } \\
\text { cohort }\end{array}$ & $\begin{array}{l}\text { Medical records of pregnant women } \\
\text { treated for DVT at one centre, } \\
\text { 1987-1994 }\end{array}$ & $\begin{array}{l}\text { Mean age } 24 \text { (range 17-39) yr } \\
\text { First trimester: } 1 \\
\text { Second trimester: } 5 \\
\text { Third trimester: } 18\end{array}$ & $\begin{array}{l}\text { Compression } \\
\text { ultrasonography, } \\
\text { venography }\end{array}$ \\
\hline James et al. ${ }^{35}$ & $\begin{array}{l}\text { Prospective } \\
\text { registry }\end{array}$ & $\begin{array}{l}\text { Consecutive pregnant patients with } \\
\text { DVT enrolled at } 183 \text { instituitions } \\
\text { from October } 2001 \text { to March } 2002\end{array}$ & $\begin{array}{l}\text { Data on age not reported } \\
\text { First trimester: } 15 \\
\text { Second trimester: } 8 \\
\text { Third trimester: } 9 \\
\text { Trimester unknown: } 2\end{array}$ & $\begin{array}{l}\text { Compression } \\
\text { ultrasonography }\end{array}$ \\
\hline
\end{tabular}


women, whereas studies published within the past 10 years $^{34,35}$ reported primarily on the use of compression ultrasonography. In all of these studies, the specific criteria for diagnosis of deep vein thrombosis with each diagnostic modality were not stated explicitly, but we assumed that they were similar to those used for nonpregnant patients. In all, deep vein thrombosis was diagnosed by venography in 55 patients, whereas compression ultrasonography was the primary mode of diagnosis for 69 patients.

Overall, involvement of the left leg was reported in 84 $(88 \%)$ of the 96 cases for which the side affected was known, and there were no bilateral thromboses (Table 2). The most common site for acute deep vein thrombosis was proximal veins without involvement of calf veins $(87 / 122 ; 71 \%)$. Among these 87 patients who had proximal thrombosis without calf vein involvement, $56(64 \%)$ had thrombosis restricted to the iliac and/or femoral vein. The prevalence of isolated iliac vein thrombosis ${ }^{29,31}$ was $17 \%(3 / 18)$, as derived from the two studies ${ }^{30,32}$ that provided specific venographic anatomic detail. Isolated thrombosis of a calf vein was reported in $6 \%$ (7/124) of cases. Ninety-five per cent (36/38) of cases of iliofemoral deep vein thrombosis were reported in the left leg.

\section{Discussion}

The majority of nonpregnant patients with deep vein thrombosis have proximal thrombosis with involvement of the calf veins $(58 \%-87 \%)$, whereas isolated proximal vein thrombi are uncommon $(0 \%-13 \%))^{1-5}$ However, in our review of deep vein thrombosis during pregnancy, $71 \%$ of the cases were restricted to the proximal veins, and $64 \%$ of these were in the iliofemoral region. These observations strongly suggest that the anatomic distribution of deep vein thrombosis in pregnant women, and perhaps the pathophysiology of the condition, may indeed differ from that reported in the general population.

The pathophysiology of iliofemoral deep vein thrombosis in both nonpregnant and pregnant patients requires further exploration. In a large retrospective study of venography performed in nonpregnant patients with deep vein thrombosis, Ouriel and colleagues ${ }^{36}$ reported that the left to right ratio was
1.3:1 for infrainguinal deep vein thrombosis but 2.4:1 for iliac vein thrombosis. The authors speculated that in a substantial proportion of nonpregnant patients with iliac vein thrombosis, there may be undetected venous webs in the iliac vein (MayThurner syndrome). In an observational study of the management of deep vein thrombosis in pregnant patients, Voke and associates ${ }^{26}$ similarly reported that the more proximal the thrombosis, the more likely it was to be on the left side. In addition, iliofemoral thromboses were also more likely to be reported in the third trimester of pregnancy.

In our current study, iliofemoral deep vein thromboses were also predominantly in the left leg $(95 \%)$. We might speculate that among pregnant women, a May-Thurner-like syndrome brought on by compression of the left iliac vein by the gravid uterus (at the point where it crosses the right iliac artery) plays a major role in the increased incidence of iliofemoral deep vein thrombosis in late pregnancy. However, given that deep vein thrombosis occurs with equal frequency in all three trimesters of pregnancy, ${ }^{13}$ this hypothesis would presumably not apply to deep vein thrombosis observed in early pregnancy.

The higher prevalence of isolated deep vein thrombosis of the proximal veins seen in this study, relative to previous studies of nonpregnant patients, is clinically important. Patients with proximal deep vein thrombosis have a high risk of pulmonary embolism (40\%-50\%). ${ }^{37}$ Untreated or unrecognized pulmonary embolism can result in maternal morbidity and mortality. ${ }^{38}$ Commonly used protocols for compression ultrasonography to diagnose deep vein thrombosis in pregnant patients (e.g., two-point compression imaging) may be limited in their ability to detect isolated iliofemoral thrombi and may therefore be inadequate. Several authors have demonstrated the feasibility of using Valsalva manoeuvres and assessing flow changes with respiration throughout pregnancy to assess the patency of proximal veins. ${ }^{39-41}$ However, the sensitivity of these manoeuvres for detecting isolated iliac vein thrombosis in pregnant women with suspected deep vein thrombosis is unknown.

\section{Limitations}

There are obvious limitations to a study of this nature. Our analy-

Table 2: Anatomic distribution of deep vein thrombosis (DVT) in 124 pregnant patients

\begin{tabular}{|c|c|c|c|c|c|c|c|c|c|c|}
\hline \multirow[b]{2}{*}{ Reference } & \multirow[b]{2}{*}{$\begin{array}{c}\text { No. of } \\
\text { patients } \\
n=124\end{array}$} & \multicolumn{3}{|c|}{$\begin{array}{l}\text { Right side } \\
n=12\end{array}$} & \multicolumn{3}{|c|}{$\begin{array}{l}\text { Left side } \\
\quad n=84\end{array}$} & \multicolumn{3}{|c|}{$\begin{array}{l}\text { Side unknown } \\
\quad n=28\end{array}$} \\
\hline & & $\begin{array}{l}\text { Isolated } \\
\text { calf DVT }\end{array}$ & $\begin{array}{c}\text { Proximal } \\
\text { with calf } \\
\text { DVT }\end{array}$ & $\begin{array}{l}\text { Proximal } \\
\text { with no } \\
\text { calf DVT }\end{array}$ & $\begin{array}{l}\text { Isolated } \\
\text { calf DVT }\end{array}$ & $\begin{array}{c}\text { Proximal } \\
\text { with calf } \\
\text { DVT }\end{array}$ & $\begin{array}{l}\text { Proximal } \\
\text { with no } \\
\text { calf DVT }\end{array}$ & $\begin{array}{l}\text { Isolated } \\
\text { calf DVT }\end{array}$ & $\begin{array}{c}\text { Proximal } \\
\text { with calf } \\
\text { DVT }\end{array}$ & $\begin{array}{c}\text { Proximal } \\
\text { with no } \\
\text { calf DVT }\end{array}$ \\
\hline Bergqvist et al. ${ }^{30}$ & $14^{*}$ & 2 & 0 & 1 & 1 & 4 & 6 & & & \\
\hline Polak et al. ${ }^{33}$ & 18 & \multicolumn{3}{|c|}{$2+$} & & & 16 & & & \\
\hline Aburahma et al. ${ }^{34}$ & 24 & & & & & & & & 5 & 19 \\
\hline James et al. ${ }^{35}$ & 34 & 1 & & 3 & 1 & 7 & 18 & & & 4 \\
\hline
\end{tabular}

*This study also included three patients whose DVT was detected indirectly, by methods other than venography. As such, the anatomic distribution of the thrombosis could not be ascertained. These patients are not represented in this table.

tIt was not possible to determine from the published article whether right-sided proximal thromboses in these patients involved the calf veins. 
sis was derived from pooling small observational studies and excluded articles in languages other than English. As such, reporting bias and selection bias are possibilities. We tried to minimize reporting bias by selecting case series of three or more patients from one site. In all six studies (case series or cohorts), determining the anatomic distribution of deep vein thrombosis, the aim of the current study, was not the primary objective. Therefore, selective patient exclusion was unlikely. That said, deep vein thrombosis of the lower extremity was assessed with compression ultrasonography in more than half of the cases. Compared with venography, compression ultrasonography is relatively insensitive for the diagnosis of deep vein thrombosis of the calf and isolated iliac vein thrombosis. ${ }^{6}$ Therefore, we might have underestimated the prevalence of isolated calf vein or iliac vein thrombosis. This might have affected our findings with respect to proximal and distal distribution of the thromboses.

\section{Conclusion}

Our primary objective in this study was to determine the anatomic distribution of deep vein thrombosis in pregnant patients. Our findings suggest that isolated proximal deep vein thrombosis, specifically iliofemoral thromboses, are common in pregnancy and that the anatomic distribution of these lesions in pregnant patients may differ significantly from that in nonpregnant women. Until prospective diagnostic studies are available for pregnant patients, it may be prudent to conduct a routine examination of the iliofemoral venous system when a pregnant patient presents with suspected deep vein thrombosis.

\section{This article has been peer reviewed.}

Competing interests: None declared.

Contributors: All of the authors, Wee-Shian Chan, Frederick A. Spencer and Jeffrey S. Ginsberg, were involved in the conception and design of the study, the writing and revision of the manuscript and approval of the version to be published.

Acknowledgements: Dr. Spencer is the recipient of a Career Investigator Award from the Heart and Stroke Foundation of Ontario. Dr. Ginsberg is the recipient of a Career Investigator Award from the Heart and Stroke Foundation of Ontario and the David Braley and Nandy Gordon Chair in Thromboembolic Disease.

Funding: No funding was received for this study.

\section{REFERENCES}

1. Cogo A, Lensing AW, Prandoni P, et al. Distribution of thrombosis in patients with symptomatic deep vein thrombosis. Implications for simplifying the diagnostic process with compression ultrasound. Arch Intern Med 1993;153:2777-80.

2. Cogo A, Lensing AW, Prandoni P, et al. Comparison of real-time B-mode ultrasonography and Doppler ultrasound with contrast venography in the diagnosis of venous thrombosis in symptomatic outpatients. Thromb Haemost 1993;70:404-7.

3. de Valois JC, van Schaik CC, Verzijlbergen F, et al. Contrast venography: from gold standard to 'golden backup' in clinically suspected deep vein thrombosis. Eur J Radiol 1990;11:131-7.

4. Habscheid W, Höhmann M, Wilhelm T, et al. Real-time ultrasound in the diagnosis of acute deep venous thrombosis of the lower extremity. Angiology 1990;41 599-608.

5. Lensing AW, Prandoni P, Brandjes D, et al. Detection of deep-vein thrombosis by real-time B-mode ultrasonography. N Engl J Med 1989;320:342-5.

6. Kearon C, Julian JA, Newman TE, et al. Noninvasive diagnosis of deep venous thrombosis. Ann Intern Med 1998;128:663-77.

7. Birdwell BG, Raskob GE, Whitsett TL, et al. The clinical validity of normal compression ultrasonography in outpatients suspected of having deep venous thrombosis. Ann Intern Med 1998;128:1-7.

8. Heijboer H, Büller HR, Lensing AW, et al. A comparison of real-time compression ultrasonography with impedance plethysmography for the diagnosis of deep-vein thrombosis in symptomatic outpatients. N Engl J Med 1993;329:1365-9.
9. Cogo A, Lensing AW, Koopman MM, et al. Compression ultrasonography for diagnostic management of patients with clinically suspected deep vein thrombosis: prospective cohort study. BMJ 1998;316:17-20.

10. Bernardi E, Camporese G, Büller HR, et al.; Erasmus Study Group. Serial 2-point ultrasonography plus D-dimer vs whole-leg color-coded Doppler ultrasonography for diagnosing suspected symptomatic deep vein thrombosis: a randomized controlled trial. JAMA 2008;300:1653-9.

11. Nijkeuter M, Ginsberg JS, Huisman MV. Diagnosis of deep vein thrombosis and pulmonary embolism in pregnancy: a systematic review. J Thromb Haemost 2006; 4:496-500.

12. Chan WS, Ginsberg JS. Diagnosis of deep vein thrombosis and pulmonary embolism in pregnancy. Thromb Res 2002;107:85-91.

13. Ray JG, Chan WS. Deep vein thrombosis during pregnancy and puerperium: a meta-analysis of the period of risk and leg of presentation. Obstet Gynecol Surv 1999;54:265-71

14. Frede TE, Ruthberg BN. Sonographic demonstration of iliac venous thrombosis in the maternity patient. J Ultrasound Med 1988;7:33-7.

15. Hull RD, Raskob GE, Carter CJ. Serial impedance plethysmography in pregnant patients with clinically suspected deep-vein thrombosis. Clinical validity of negative findings. Ann Intern Med 1990;112:663-7.

16. Ginsberg JS, Brill-Edwards P, Burrows RF, et al. Venous thrombosis during pregnancy: leg and trimester of presentation. Thromb Haemost 1992;67:519-20.

17. de Boer K, Büller HR, ten Cate JW, et al. Deep vein thrombosis in obstetric patients: diagnosis and risk factors. Thromb Haemost 1992;67:4-7.

18. Gherman RB, Goodwin TM, Leung B, et al. Incidence, clinical characteristics, and timing of objectively diagnosed venous thromboembolism during pregnancy. Obstet Gynecol 1999;94:730-4.

19. Soomro RM, Bucur IJ, Noorani S. Cumulative incidence of venous thromboembolism during pregnancy and puerperium: a hospital-based study. Angiology 2002;53:429-34.

20. Adachi T, Hashiguchi K, Arai Y, et al. Clinical study of venous thromboembolism during pregnancy and puerperium. Semin Thromb Hemost 2001;27:149-53.

21. Tutschek B, Struve S, Goecke T, et al. Clinical risk factors for deep venous thrombosis in pregnancy and the puerperium. J Perinat Med 2002;30:367-70.

22. Weiss N, Bernstein PS. Risk factor scoring for predicting venous thromboembolism in obstetric patients. Am J Obstet Gynecol 2000;182:1073-5.

23. Blanco-Molina A, Trujillo-Santos J, Criado J, et al.; RIETE Investigators. Venous thromboembolism during pregnancy or postpartum: findings from the RIETE Registry. Thromb Haemost 2007;97:186-90.

24. Le Gal G, Prins AM, Righini M, et al. Diagnostic value of a negative single complete compression ultrasound of the lower limbs to exclude the diagnosis of deep venous thrombosis in pregnant or postpartum women: a retrospective hospitalbased study. Thromb Res 2006;118:691-7.

25. Kierkegaard A. Incidence and diagnosis of deep vein thrombosis associated with pregnancy. Acta Obstet Gynecol Scand 1983;62:239-43.

26. Voke J, Keidan J, Pavord S, et al.; British Society for Haematology Obstetric Haematology Group. The management of antenatal venous thromboembolism in the UK and Ireland: a prospective multicentre observational survey. Br J Haematol 2007; 139:545-58.

27. Spritzer CE, Evans AC, Kay HH. Magnetic resonance imaging of deep venous throm bosis in pregnant women with lower extremity edema. Obstet Gynecol 1995;85:603-7.

28. Polak JF, O'Leary DH. Deep venous thrombosis in pregnancy: noninvasive diagnosis. Radiology 1988;166:377-9.

29. Aburahma AF, Bastug DF, Tiley EH 3rd, et al. Management of deep vein thrombosis of the lower extremity in pregnancy. WV Med $J$ 1993;89:445-7.

30. Bergqvist A, Bergqvist D, Hallböök T. Deep vein thrombosis during pregnancy. A prospective study. Acta Obstet Gynecol Scand 1983;62:443-8.

31. Bergqvist D, Hedner U. Pregnancy and venous thrombo-embolism. Acta Obstet Gynecol Scand 1983;62:449-53

32. Greer IA, Barry J, Mackon N, et al. Diagnosis of deep venous thrombosis in pregnancy: a new role for diagnostic ultrasound. Br J Obstet Gynaecol 1990;97:53-7.

33. Polak JF, Wilkinson DL. Ultrasonographic diagnosis of symptomatic deep venous thrombosis in pregnancy. Am J Obstet Gynecol 1991;165:625-9.

34. Aburahma AF, Boland JP. Management of deep vein thrombosis of the lower extremity in pregnancy: a challenging dilemma. Am Surg 1999;65:164-7.

35. James AH, Tapson VF, Goldhaber SZ. Thrombosis during pregnancy and the postpartum period. Am J Obstet Gynecol 2005;193:216-9.

36. Ouriel K, Green RM, Greenberg RK, et al. The anatomy of deep venous thrombosis of the lower extremity. J Vasc Surg 2000;31:895-900.

37. Huisman MV, Büller HR, ten Cate JW, et al. Unexpected high prevalence of silent pulmonary embolism in patients with deep venous thrombosis. Chest 1989;95:498-502.

38. Lindqvist P, Dahlback B, Marsal K. Thrombotic risk during pregnancy: a population study. Obstet Gynecol 1999;94:595-9.

39. Macklon NS, Greer IA, Bowman AW. An ultrasound study of gestational and postural changes in the deep venous system of the leg in pregnancy. Br J Obstet Gynaecol 1997;104:191-7.

40. Duddy MJ, McHugo JM. Duplex ultrasound of the common femoral vein in pregnancy and puerperium. Br J Radiol 1991;64:785-91.

41. Palmgren J, Kirkinen P. Venous circulation in the maternal lower limb: a Doppler study with the Valsalva maneuver. Ultrasound Obstet Gynecol 1996;8:93-7.

Correspondence to: Dr. Wee-Shian Chan, Department of Medicine, Women's College Hospital, 76 Grenville St., Toronto ON M5S 1B2; wee-shian.chan@wchospital.ca 